\title{
Impact and Analysis of Performance Appraisal on Employee's Motivation and Its Effects on Employee Retention in Banking Sector in COVID-19
}

\author{
Muhammad Faisal ${ }^{1}$, Umar Faryaz ${ }^{2}$, Qamber $\mathrm{Ali}^{3}$, Sana Khan ${ }^{4}$ \\ ${ }^{1}$ College of Business Management, Institute of Business Management, Karachi, Pakistan \\ ${ }^{2}$ Department of Mathematics, NED University, Karachi, Pakistan \\ ${ }^{3}$ Department of Business Administration, Iqra University, Karachi, Pakistan \\ ${ }^{4}$ Department of Business and Management Sciences, Superior University, Lahore, Pakistan
}

Email address:

Faisalumar1992@gmail.com (M. Faisal)

\section{To cite this article:}

Muhammad Faisal, Umar Faryaz, Qamber Ali, Sana Khan. Impact and Analysis of Performance Appraisal on Employee's Motivation and Its Effects on Employee Retention in Banking Sector in COVID-19. European Business \& Management. Vol. 7, No. 5, 2021, pp. $133-151$. doi: $10.11648 /$ j.ebm.20210705.11

Received: July 26, 2021; Accepted: August 10, 2021; Published: September 10, 2021

\begin{abstract}
One of the core principals of Human Resource Management is Performance Appraisal and it basically is a win-win situation in both aspects because employee gains benefits in terms of rewards, bonuses and management targets and objectives are fulfilled. In this research we have analyzed performance in keeping in view of Management. For this purpose, we have conducted an empirical study of the staff members keeping in view of banking sector and data has been collected through questionnaire. We have established the relation between performance appraisal and work motivation which depends on performance appraisal types used in Banking sector and transparency of the process of performance appraisal, which is carried out are merely shared to employees only rating and appraisal letter is disseminated so therefore it impacts a downfall on employee engagement and employee gets demotivated if appraisal cycle is not conducted transparently which results in turn over. We have studied different performance methods which are implemented in organizations and tried to generate a new appraisal method keeping in view of COVID-19 and modern changes implemented in current era. We have reached out a point that employee should be educated about performance appraisal method so that it can be more effective and plays a positive role in building future leaders and increase organization profitability and maintain a healthy culture in an organization. Modern Banking has been digitalized and transformed in current era where technology plays a vital role and people get benefited in their homes due to advancement and current pandemic situation which arises it is important that smart work should be implement in combination of working from home and physical presence of employees so that organization work can be easily be done and more customer can be facilitated. We have reached at a point that employee training and education shall be prevailed related to digitalization and shall be aware about his JD and KPI's respectively so that his appraisal can be done in an effective way which results in employee retention and organization profitability. It is concluded that combination of 360 degree appraisal and Human Resource Cost Accounting method shall be implemented as a new appraisal methodology which can be successful in keeping employee retention and playing a positive role in organization goals and objectives. If employees are not involved in financial benefit of an organization in that case we have to convert impact of his performance which results in achieving organizational goals and objectives.
\end{abstract}

Keywords: Performance Appraisal, Employee Engagement, Organization Goals and Objectives, Employees Motivation, Financial Objectives 


\section{Introduction}

\subsection{Human Resources Role in an Organization}

Human resources are an essential part in any organization and is of the most important and critical department. If Human Resources or employee of the respected organization is happy so therefore, they will try to do their level best to make an organization profitable. Employees working in an organization gets rewarded which results in better satisfaction and boost up performance of employee's performance if it is done in a systematic way. Employees get motivated when they are rewarded against their task and performances fulfilled on the yearly base.

It has been observed that employee's performance is boosted and exceeded up to the mark if they are being rewarded properly by an organization. The performance appraisal is the process in which performance of the employee is being collected, targets achieved against objectives is being analyzed along with personal development and professional grooming that is done throughout the appraisal cycle. Major purpose of performance is to improve the actual purpose of hiring an employee, determine future potential, measure, calculate the manpower required to grow and run the current and future business. It focuses on improvement of existing issues so that employees are able to perform their level best for future.

Performance appraisal is a regular exercise done on yearly basis in order to measure performance of an employee within organization and its aim is to

1) Identification on employee weakness and provide them training.

2) Allocation of rewards as per defined criteria.

3) Formulate decision i.e salary increase promotion, disciplinary action etc.

4) Opportunity of providing organizational development and diagnosis of pros and cons.

5) Bridge a communication gap between employee and management.

It is a tool to measure, refine and to appraise the performance of an employee, it is helpful in calibration of employee's achievement and examine his useful contribution toward the organization targets and goals. Performance appraisal reflects the personal interest and progress of employees.

People are different in their ability and aptitude so therefore each and every person has different caliber and aptitude of grasping the things so therefore it is necessary while conducting appraisal it is necessary to understand each and every employee mindset and their valuable contribution towards the organization.

OECD policies [7] has recently indicated that jobs are more prone towards technological aspect as more preference has been given to remote working in order to avoid spreading of pandemic.

Impact of Performance appraisal on Employee retention by Saba Gulzar and Dr. Avinsah [8] has also mentioned that banking industry is facing an issue related to employee turnover rate because of inadequate policies of $\mathrm{HR}$ in banking sector.

Performance appraisal role has a positive impact as discussed in Role of Performance Appraisal System and Its Impact on Employees Motivation by Pooja [9] in which she determines determine the extent to which appraisers affect staff motivation and to determine the challenges in appraising employee performance.

The COVID-19 [10] pandemic presented huge challenges to all aspects of life including social, economic, public health, governmental and business activities.

COVID-19 [11] pandemic has affected the customer relation management CRM function in the Middle East.

Emergency Management [12] is another field of study and practice that continues to shape human resource management practices. Due to many notable natural and manmade disasters organizations have designed programs and policies to ensure mission-essential organizational functions continue regardless of internal or external threats of disruption to operations.

Returning employees to the workplace during the COVID19 [13] pandemic requires both vigilance and flexibility to navigate uncharted territory. HR needs to stay up-to-date and ready to respond as threats and opportunities occur.

The COVID-19 [14] pandemic presented huge challenges to all aspects of life including social, economic, public health, governmental and business activities. Following a year of mandatory closures and quarantine, there is new hope in the fight against the virus as vaccines and new safety precautions have been implemented globally, but the crisis is not over yet.

A central aim of human performance technology (HPT) practice [15] is to produce desirable results that are valuable to both the organization and the organi-zation's employees by implementing effective and efficient interventions. To increase the probability of producing desirable results, it is important to utilize both systematic and systemic processes (Stolovitch \& Keeps, 1999). Simply put, a systematic approach refers to constructing and following a step-by-step plan, similar to climbing a ladder one step at a time or following a road map, until reaching the desirable performance level. A systemic approach refers to considering all the necessary components that are mutually influential on one another by identifying often complex linkages among them.

Performance appraisal is a key method in the rating of the staff in terms of their performances. It takes into measure of the past performances of the respected staff and it focuses on the betterment of the future performance and grooming of the employees. The study of the performance appraisal of staff was being carried out at the Banking Industry. The aim of this study is to explore the methods which results in the effectiveness of the employees. Primarily the data which is required was being conducted through questionnaire interview and informal discussion, while the secondary data has been collected from the company manuals and websites. The data has been analyzed using SPSS and findings are 
being made through valuable feedback and statistical analysis.

\subsection{Problem Statement}

In the current era where the technological aspects are enhanced provides a great deal of communication with fewer efforts from employees. Organization expects a great deal employees to perform more effectively and efficiently. Performance appraisal is designed to capitalize the potential of an employee by up bringing him to managerial position. It's an opportunity for an employee to improve his quality of living and improving his work life balance. Problem arises when an organization focus on saving by comprising quality due to cost cutting factor in addition to its quality staff is not getting market compatible rate so therefore they get demotivated and frustrated if an industry is not providing them appraisal as per their quality and achievements. Organization that provides market compatible appraisal can expect employees to perform more but on the other hand if an employee is not being rewarded to the mark so therefore his potential performance and moral gets low.

In some cases workers in a company does not receive adequate bonuses and incentives due to which it adequately inactive the level of performance their jobs. However problems for both organization and employee are listed below:

1) Low production and profit margin;

2) Making inferior products;

3) Poor customer services and satisfaction;

4) Insatiable demands from employees.

\subsection{Performance Appraisals}

Performance appraisal is a core process of accessing, summarization and development of workforce of an employee in order to be more effective and positive, the supervisor should make an effort to obtain sufficient information about employee's performance as much as possible. In adequate and low performance can push an organization back in competitive scenario. The research paper is designed to analyze performance appraisal in Banking Sector.

\subsection{Objectives}

The primarily purpose of the research is to provide feedback to individual employees so that they came know that where they stand and improve performances. Aim is to provide them knowledge how decision is taken by an employer keeping in view point performance. This includes placement, rewards, re-designation, promotion or punishment etc.

1) It is use for diagnose of strengths and weakness in order to identify weak points and provide them training.

2) In order to provide them counseling, career planning and path to treat sub ordinates.

3) In order to facilitate research for personal management and counseling.
4) In order to test employee's effectiveness of recruitment selection and placement of induction programs.

5) Attitude of employees towards the performance appraisal system.

6) To identify key performance parameters in order to measure organizational effectiveness.

7) To study the results applied on the productivity of employees through performance appraisal.

8) To improve Key Performance Indicators in order to achieve organizational goals and success.

\subsection{Analysis and Surveying Structure}

It is important to know ground realities of employees working in an organization whether they are contented or demotivated with an existing organizational structure due to current situation of COVID-19 employment is getting reduced and employees are doing work of multiple people due to non-availability of resources.

Employees are an asset in an organization and can led to future progress of growth of an organization if they are properly appreciated and rewarded so therefore primary issue of employees are necessary to be pointed out that what issues they are facing in the existing structure and to identify their grievances so that organization try to resolve their issues which result in employee satisfaction and growth and can increase profitability.

Keeping in view of this case various employees were met and issues of them were highlighted so therefore questionnaire has been desired as per their problems. Data of employees were recorded through SPSS and analysis is being made in order to find out productivity of employee and fair pay methodology.

\subsection{Purpose of Performance Appraisals}

\subsubsection{Development of Existing Structure}

It helps to highlight the weakness in staff and work on the effective by mentoring, counseling and providing them training.

\subsubsection{Rewards}

It helps in determination of who should receive award and who shall be transferred to the other respected domain as per expertise.

\subsubsection{Motivation Purpose}

It helps in gel up of employees and realizes their efforts.

\subsubsection{Legal Purpose}

It provides a legal aspect in making transfer, rewards, promotion, demotion and discharge decisions.

\subsubsection{Compensation}

It helps to identify what pay and package is an market compatible as per market demand.

\subsubsection{Value Understanding}

Supervisor and employee get to know about each other through which criteria performance has been awarded. 


\subsubsection{Human Resources and Man Power Planning}

It proves to a valuable asset in engagement of HR and workforce planning in which department skills and workforce is required.

\section{Literature Review}

\subsection{Objective of Study}

It is a general that appraisal as a technique that can motivate to employees towards greater productivity and it results increases profit.

Since, the objectives of this study is to:

1) To determine the relation between Performance appraisals and Employee motivation.

2) To examine the effect of upper class and lower worker appraisals this can motivate employees in an organization.

3) To identify the existing pros and cons of appraisal process and suggest changes in loopholes.

\subsection{Significance of Study}

There is need of this research of this type at a time when questions arises are being asked to the practical and basics of performance appraisals which effects on employee's motivation in any organization.

Study will provide us modern equipped knowledge of the following categories of employees:

a) Managers of organization;

b) Employees and workers in any organization;

c) The group heads;

d) Clerical staff;

e) Research associates this particular topic;

f) Benefits the society.

\subsection{Literature Review of Performance Appraisals}

This act of motivating employees is the basics of the organization. Achievements in an organization depends upon person motivation appraises by their respective directors.

Greater the proficiency of the employees and presenting them rewards and benefits as a sign of motivation, so that they can improve their performances is one of the the primary factors in performance appraisal. Performance appraisal dates can be regarded as important elements in personnel management and part of the management process.

Much research has been done earlier in performance testing. Investigators found different results from that study. In addition, texts were reviewed and based on these revisions, the hyporesearch paper was developed.

A study was conducted in Peninsular Malaysia where it was found that satisfaction with performance appraisal has a positive effect on performance and job commitment. This was quantitative research and adjustment and retrospective analysis used to analyze the outcome of the study.

Some studies have shown that performance appraisals are closely related to job commitments, internal motivation linking work relationships and performance balances.

\subsubsection{The Concept of Performance Evaluation}

While many organizations continue to use informal performance appraisal methods to make reward decisions, there is evidence that purposeful performance appraisal practices are on the rise in modern times. Gardner defines performance appraisal as a performance evaluation of a person with the primary purpose of reaching purposeful employee decisions. It is also viewed as a process of finding, analyzing, and recording information that surrounds the value of an employee in an organization. This is due to a systematic collaboration between the directors of the organization and the staff in which the former assesses the effectiveness of the past. One of the main objectives of this case is to identify the strengths and weaknesses that form the basis of action recommendations to improve staff performance.

The practice of evaluating the performance of employees is an important factor in creating organizational inequalities. Organizational justice has been defined as the individual's view of honesty and integrity in the administration of the organization. Organizational justice has the potential to create benefits for both the employee and the employer including greater commitment, improved work performance, improved customer satisfaction and reduced organizational conflict. In the PA process, there are two methods used to determine whether a PA system is right or wrong and this is process and distribution justice. Procedural fairness informs employees that the procedures used to test their performance are fair and that equity fair means that input is tantamount to dismissal. Research has also shown that there is a link between organizational bias and work ethic. The effectiveness of PA is determined by the views of employees. If employees see that PA favors a particular type of group and not everyone and that there is no relationship between the employee itself and the PA system, this makes the system ineffective and frustrating. A systematic review system is helpful to employees if it is considered inappropriate. In order for employees to accept the system as fair, certain conditions must be met, including: employees must have professional knowledge of the work; there must be an application forum for the response received; the equipment used for exercise should work; and how to deal with challenges as they arise.

\subsubsection{Performance Test Response}

Feedback is an important part of the PA program, which is provided extensively by the person during and after the completion of the performance review. Performance feedback is a key function of the PA process in organizations and no organization can improve productivity where employees do not know how to work in line with the organization's stated objectives. Performance analysis is used for management decisions, such as promotions, salary increases, and terminations, and for development purposes. Therefore, the main function of the performance response should be to better performance with the aim of increasing the value and quality of the product from the employees through promotion. It is therefore important to communicate 
regularly about the progress of the workforce that leads to the full growth of the workforce.

Performance feedback is important to employees and the organization where it is provided in a timely manner because it helps to create performance measures where necessary while it is still clear and acceptable to employees. This promotes better job development and staff growth.

Systematic performance analysis helps employees understand the vision the organization has for them and the value they hold on to. Feedback from employees can be very important information about the PA program that employees receive from the organization in terms of actual values that reflect the values, value, and future prospects of the organization.

The Performance Appraisal is a tool that can be used to manage performance effectively, as it provides information, which goes into other parts of the performance management process. When used for the intended purpose, PA contributes to motivation, improved performance and efficiency. Mathis and Jackson reduce the use of PA by two phases administrative use and development use. In administrative work, it is used to determine the salaries of employees, promotions among others. While the implementation of development is focused on building and strengthening the capacity of workers and building their work ethic.

In practice, PA serves as an incentive for career advancement through recognition, salary increases, promotions, and challenging responsibilities. For the manager, Performance Test works to direct you to tasks such as determining employees' salaries. Promotion along with others.

In administrative work, it is used to determine the salaries of employees, promotions among others. While the implementation of development is focused on building and strengthening the capacity of workers and building their work ethic.

In practice, PA serves as an incentive for career advancement through recognition, salary increases, promotions, and challenging responsibilities. As a manager, the Performance Appraisal works to oversee activities such as determining staff eligibility for training, salary increases and termination.

The research will help establish the best way to use a performance appraisal system to motivate employees and as a monitoring tool that will help the company track progress and know when to change course.

Motivation is eagerness and responsibility, marked as hard work. Some people want to finish the assignment but are distracted or discouraged. They have a high desire but a bad assurance. Another great thing and a strong determination, but their work is unthinkable. These people have high commitment but have low ambition.

They show the need for improvement: If employees do not have a clear understanding of how they have been performing, they may not be motivated to make any progress. They meet the highest psychological needs: Researchers continue to find that recognition is one of the most powerful ways to motivate a large number of employees. While you can find many sources of honor in the workplace, performance appraisals are an opportunity for employees to gain legitimate, significant and long-term recognition from their boss.

They create a sense of personal value: When managers take the time and effort to carefully review, analyze, document, and discuss employee performance, the basic message to employees is that they are important and valuable, and this alone is rewarding, whether the response is constructive or not.

They promote personal development: Performance assessments are encouraging for employees who want to improve their learning, growth, and development. Assessment is the most important source of information, understanding, and tools needed for that progress. Performance appraisals similarly encourage employees with needs that focus on achieving, achieving goals, and recognizing personal performance, respect and trust.

Meier, Kenneth J. \& Hicklin. Alisa describes employee turnover has negative effect on an organization as organization performance decreases downwards due to employee motivation which results in turnover.

Turning employees away: When employees misbehave, performance tests can give a wake-up call that they need to be re-evaluated and re-enabled. For performance testing, however, the purpose of the session is not for disciplinary purposes, so the employee is likely to enter with a welcoming and open mind. As a result, your comments about the employee's questionable performance have a very good chance of being heard and acting as a result.

Increase Satisfaction: When performance appraisal meets the needs of employees in areas such as gaining recognition, achieving success and competence, achieving growth, and achieving goals, it also contributes to job satisfaction for employees, and this is one of the best key elements working today. When employees are satisfied, some of the most obvious indicators are low profitability, unemployment, and timeliness.

The following are some of the definitions that begin to help us think of this unattainable concept.

Iv Motivation is a precursor to working on an incomprehensible goal aimed at the path. (Hellriegel and Slocum).

Motivation may be as diverse as a person's mental state, representing the power of his or her tendency to make certain deceptive attempts. (Gibson).

1) Employee motivation as the process of moving an employee to work. While explaining the motive of the staff in detail.

2) Wolff and Gunkel [1] argue that enthusiasm often arises from a psychological need that goes hand in hand with the need to satisfy unsatisfied desires.

Promoting a process that empowers employees and motivates them to pursue their goals. Well-designed and well-executed performance tests have a strong motivating effect. Testing has the potential to motivate employees 
because they offer many connected benefits. The award system for most organizations is based on performance appraisal by management. PA is a process of setting standards, evaluating the performance of employees against standards, providing feedback to employees on their performance and developing plans to improve performance. Performance appraisals are conducted on staff with the aim of motivating them and increasing commitment, which leads to higher productivity, and also with the aim of directing the work efficiently.

Encouraging employees to do better and increase productivity is not an easy task. In any organization, employees are motivated by internal or external needs, so it is the responsibility of the manager to understand the structure of employees or this is most likely by performance appraisal.

From a staff perspective, internal motivation is seen as a motivating factor that takes on the characteristics of doing the work for it. In addition, internal motivation is defined as one that provides employees with the psychological benefits of well-being, self-care, increased responsibility and selfsufficiency.

External motivation has been defined in the labor sector as the importance of employees in external rewards, which may include promotions and salary increases (token). It can also include negative aspects such as the threat of dismissal or demotion. From a theoretical point of view, agency theory suggests that the incentives offered by organizations as a way to increase employees' internal motivation are often significant. The reason in this case is that the actions of employees are rewarded or punished which is why the action and performance of employees is determined. While external factors such as pay are often considered to be a positive factor in motivating employees, many investigators say they may be somewhat underestimated, for example, realized that overemphasizing external stimuli could distract the employee from focusing on the task at hand. Two authors view this effect as a hidden reward cost.

Several studies suggest the existence of a positive relationship between internal and external motivation and subsequent effect on performance. This good relationship is well described in Theory of Hygiene Theory of Herzberg. From this perspective, the elements of internal motivation include work itself, recognition and personal success. External factors on the other hand are aspects of hygiene that include remuneration and supervision. When linking internal and external motivation, Herzberg noted that hygiene factors lead to job satisfaction as part of the process of internal motivation because they satisfy people's internal need to do it yourself. The argument in this case is that internal and external factors combine to have a positive impact on employee performance.

Motivation is very important in the organization of the organization. Its value lies primarily in the conduct of human behavior, in directing and regulating that behavior and in maintaining it. In this context, Emmerik, Schreurs, Cuyper, and Peters say that performance appraisal can be used to motivate employees with rewards such as promotions and salary increases. According to Herzberg, such rewards are in the form of external prizes that can be used to increase performance.

As part of the performance appraisal process, inspectors measure job performance and provide a performance number. The operational number also leads to the development of a standard operating number (LPN) used by management as a reward platform as part of the promotion process. Whenever there are new job openings beyond the entry level, the LPN becomes a useful reference point for managers who can use it for internal promotions. Such promotions not only serve as a reward for past employee performance but also play a key role in sending a message to colleagues that their future hard work will be truly rewarding. Therefore, some employees in the organization are encouraged to improve their performance.

Within the performance management books one of the most prominent views is that money or pay for work is one of the most effective ways to reward employees and therefore the promotion is increasing. Money in this case serves as an external incentive to meet the needs of employees indirectly through bonuses and payments. Jensen and Murphy while defining a pay-per-view concept in the consolidation concept, suggest that compensation, can be linked to performance by setting specific objectives. Employees are rewarded according to their ability to achieve these goals. External motivation to get more out of this case affects employees to make more effort and better performance. In the calculation of bonus payments, the sales department and the HR department can set the expected performance level as the number of units sold. Employees who exceed the thresholds receive incentive payments such as an additional 2 percent at a given level of sales statistics. Performance testing helps the whole process.

Performance appraisals have also been found to serve a useful purpose in motivating employees by providing a platform for successful recognition. Admission in this context includes the distribution of non-financial personal rewards that help to strengthen the ethical behavior displayed by the employee. It involves a lot of praise in praise; awards such as certificates of achievement and independent budgets; and ceremonies such as public ceremonies and speeches. Past studies in this area suggest that managers and other managers should see the efforts of their employees as such behavior can create the design and implementation of behaviors that lead to better performance.

An independent variation of this study is performance appraisal, which has been used appropriately: to set workrelated goals; employee participation; process bias; timely response; and the use of results. Dependent diversity is the motivation of employees, which is reflected in the willingness, collaboration, problem-solving, and quality of work with motivated employees.

The employer selects the PA as the performance measurement tool. The management of the assessment tool has the potential to disrupt or motivate employees to meet the objectives of the organization. The issuance of the PA 
process transfers to the employer the number of employees the organization manages.

\subsubsection{Hypothesis}

According to the literature review, all the variables including the variance of dependence and autonomy are visible, now based on these variables, the theory in the study is made as "Performance appraisal has a positive impact on the motivation of the employee."

Independent Variables

Dependent Variables

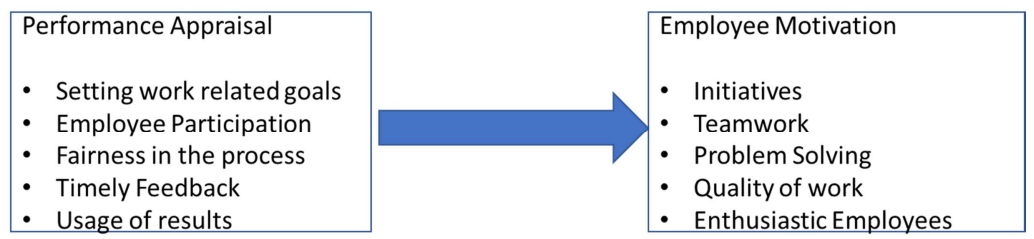

Figure 1. Performance appraisal has a positive impact on motivation of employee.

\subsubsection{Bell Curve}

A Bell curve is a common type of flexible distribution, also known as a common curve. The term "Bell curve" is derived from the fact that the graph used to show the general distribution contains a curved bell curve.

The highest point at the curve, or at the top of the bell, represents the most likely event in the data chain (i.e., mode, and community in this case), while all other events are evenly distributed over the mean, making a downward curve on each side of the peak. The width of the bell curve is defined by the standard deviation.

The curve is a graph showing the general distribution, with a shape reminiscent of the bell.

Its general deviation indicates the width of the bell type around the mean.

Bell curves (general distribution) are widely used in statistics, including analysis of economic and financial data.

The term "bell curve" is used to describe a clear representation of a common, general deviation from the basic definition from the definition that forms a curved bell shape. The standard deviation is the measure used to measure the variability in the scattering of data, in a set of values given around the definition. The description, in turn, refers to the normalization of all data points in a data set or sequence and will be located at the top of the bell corner.

Financial analysts and investors often use a general spread of opportunities when analyzing the return on security or the overall sensitivity of the market. In finance, a general deviation from the return on collateral is known as volatility.

For example, stocks with a curve of steel are usually blue and those with low volatility and unpredictable behavior patterns. Investors use the standard distribution of pre-term stock options to make assumptions about future expected returns.

In addition to teachers using the curve when comparing test scores, the curve is also widely used in the mathematical world where it can be widely used. Bell curves are also sometimes employed in performance management, placing employees who perform their work in a normal way in the normal distribution of the graph. The top players and the lowest players are represented from side to side with the downhill slope. It can be useful for large companies when conducting performance reviews or when making management decisions.

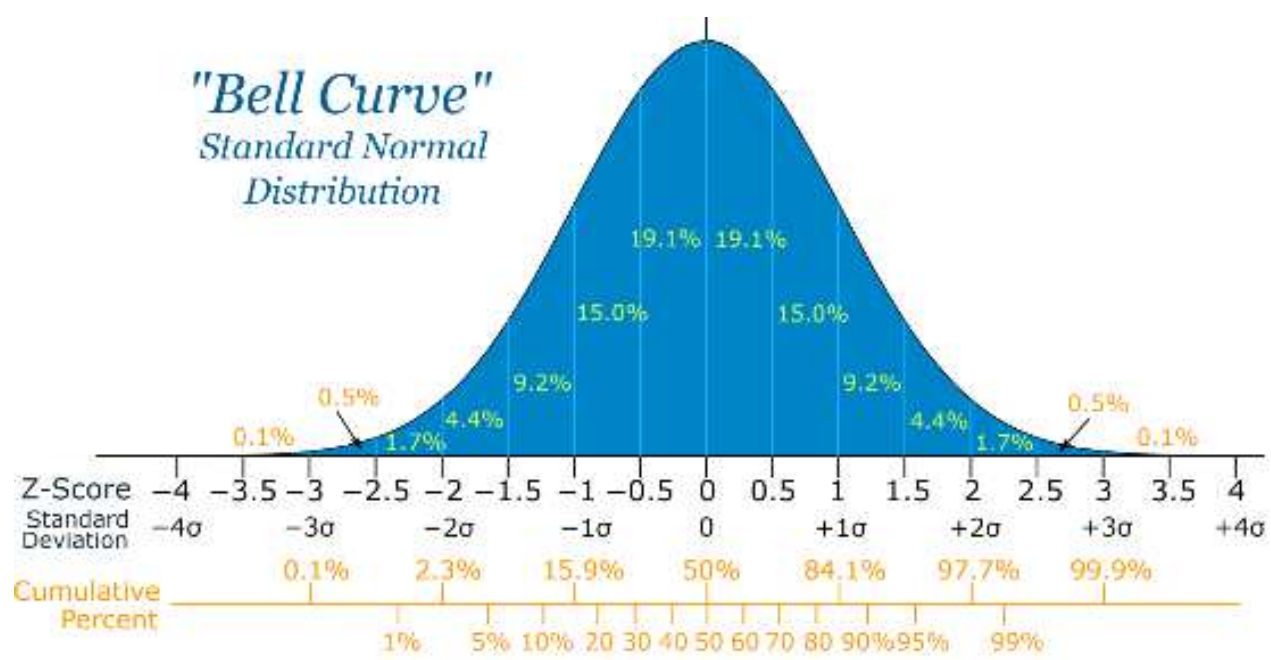

Figure 2. Bell curve for Standard Normal Distribution. 


\subsubsection{Degree Appraisals}

A 360 degree appraisal involves obtaining feedback not only from the direct supervisor but also from other employees, including co-workers and subordinates. As a result, employers are able to complete a more thorough assessment of an employee's performance. However, are there any disadvantages associated with conducting a 360 degree appraisal.

Since a 360 degree appraisal encompasses consideration of feedback from various parties, sometimes the feedback obtained can be influenced by different factors or even skewed by underlying motives. With that in mind, write a short essay made up of a few paragraphs discussing whether the objectives of a 360 degree appraisal should be focused on employee growth and development or employee compensation and promotions. Ensure you include a discussion about which objectives would be more advantageous to focus on and why that approach would be more beneficial.

The 360-degree performance testing policy is very complex and difficult to implement. One might ask why an organization should invest in a 360 degree performance appraisal program? Here is the answer, which is about longterm employee development and building strong leadership. The 360 degree performance appraisal system provides a comprehensive approach to staff performance. It covers the most important things like collaboration, collaboration and leadership. The development program, based on a 360-degree performance appraisal system, effectively enhances the overall employee performance and productivity of the organization. There are various steps we follow to do a 360 degree test. The clarity and effectiveness of the plan is very important to the organization.

\subsubsection{Behaviorally Anchored Rating Scale (BARS)}

Estimates are designed to deliver the benefits of quality data and value in the employee evaluation process. BARS compares human performance by comparing certain behavioral models that adhere to price estimates.

For example, a fourth level nurse may require them to show empathy for patients while a sixth degree may require them to show high levels of empathy and ensure that this is found in all patient interactions.

Examples of behaviors used as anchor points are usually collected using Critical Incident Strategy (CIT), which are procedures used to record important human behavior in a particular area.

BARS was initially developed to combat the perceived concept of using basic measures to judge performance, although BARS is still under criticism. It is often accused of being under the guise of dishonesty and negligence.

\subsubsection{Assessment Center}

It is a place to assess the strengths of each person and their performance, so that they are placed in functional areas. generally, organizations issue Assessment centers without doing it themselves.
The Assessment center involves the use of methods such as public / informal events, exercises and exercises, assignments assigned to a team of employees to assess their ability to take on higher responsibilities in the future. Typically, employees are assigned a task similar to the one they were expected to perform when promoted. Qualified inspectors monitor and evaluate employees as they perform their assigned tasks and are evaluated on job-related aspects.

Major skills are judged in Assessment centers for interpersonal skills, mental strength, planning and organizing skills, motivation, job training etc. Assessment center are also an effective way to determine the training and development needs of targeted employees.

About $30 \%$ of companies seek the services of a Assessment center while moving an employee from management to management. $20 \%$ of companies claim to use institutional services when seeking position at senior management level.

According to TJinsite, a premium research website sponsored by TimesJobs.com, more than $80 \%$ of surveyed employers predict an increase in the use of Assessment center in the near future due to their expertise and impartiality in assessing equality and limited limitations.

\subsubsection{Psychological Testing}

It helps to determine the hidden power of employees. This approach focuses on analyzing the future performance of an employee rather than their past work. This assessment is used to analyze seven major components of employee performance such as interpersonal skills, cognitive skills, intelligence skills, leadership skills, personality traits, emotional quotient, and other related skills.

Qualified psychologists perform a variety of tests (in-depth interviews, psychological tests, interviews, and more) to assess the employee's effectiveness. However, a slow and complex process and the quality of results depends largely on the psychologist who controls the process.

Certain conditions are considered during a psychiatric examination. For example, the way an employee deals with an aggressive customer can be used to measure his or her persuasive skills, behavioral response, emotional response, and more.

Benefits of a psychiatric examination:

Extract measurable data, with the purpose of not only employee performance but also power. It can be easily installed compared to other performance testing methods.

Provide quiet or shy employees with a platform to light up and prove their strengths.

Big business can use mental balance for many reasons including building a leadership pipeline, team building, conflict resolution and more.

Common reasons for failure:

Lack of proper training, lack of trained professionals to provide updates, and panic or concern for candidates can affect results.

Did you know? 
Ford motors, Exxon Mobil, Procter \& Gamble use psychological appraisals to assess the personality and performance of their employees.

\subsubsection{Staff Compensation Method}

Employee accounting (cost) measures an employee's performance against the financial benefits he or she receives from the company. It is obtained by comparing the cost of maintaining the work (costs to the company) with the financial benefits (contributions) the organization received from that particular work.

When employee performance is assessed based on costing methods, factors such as limited service value, quality, high cost, interpersonal relationships, and more are considered. Relying heavily on cost and benefit analysis of the reviewer's memory is to go back to the staff accounting system.

Advantages of a personal cost calculation method:

Measure well the cost and the amount that an employee brings to the organization.

Help identify the financial implications of employee performance on the organizational line. Starting with small businesses where the performance of one employee can make or break an organization's success.

\subsubsection{Implementation of Personnel Cost Calculation Method}

Identify the gap between the current market and the employee package. Determine the amount of money and noncash that the employee brings to the table. Write down the things the job gained during the review (increase in enrollment, improvement in income, number of new deals earned, etc.).

A future-oriented performance appraisal system.

Choosing the right performance appraisal is more important than ever because it reflects what you think about your employees and how much you care about employee behavior. Once you have found the right approach to performance appraisal of your needs, the next step is to use it effectively to eliminate critical workflows and address stressful issues that contribute to ROI.

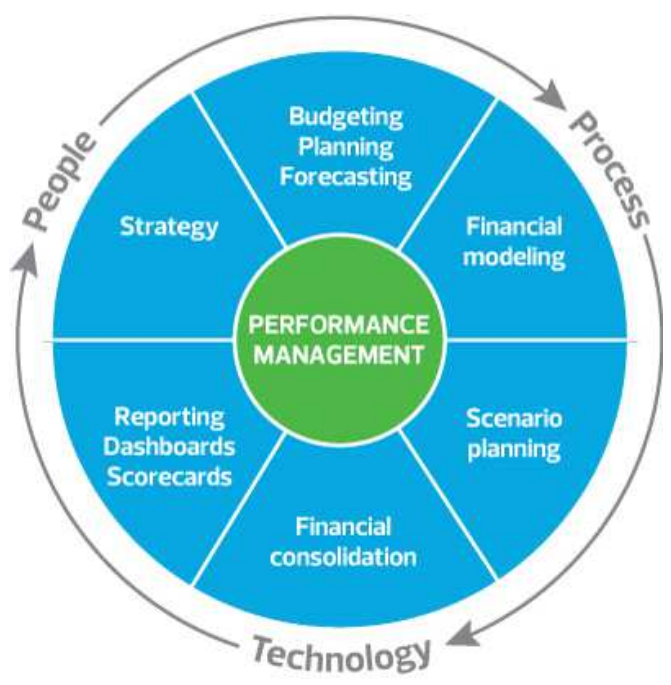

Figure 3. Performance Management.

\section{Methodology}

\subsection{Research Methodology}

This chapter is about discussing the research methods of the researcher in completing the study purposefully and logically. Some of the most important factors considered here are the methods, philosophy, and research paradigm, as well as data collection methods and analytical methods.

\subsection{Research Method}

Educational researchers such as Bryman Adams, Khan and Raeside [3] have come up with two types of studies. This is slower and slower. The first works on the formation of theoretical view on the basis of the facts presented; whereas, the latter supports the formation of the hyporesearch paper and explores it with the help of previously established theories Easterby-Smith, Thorpe and Jackson [4]. In the present study, the researcher has tried to integrate the deduction method and the reason for this is to prove whether there is an important and positive relationship between employees and the employer and whether they have sufficient motivation for their work. The selected method continues to test the measurement tests and as a result, it is easier to analyze the power to which the specified features are connected.

\subsection{Research Strategy}

According to Hair and Lukas [5], the implementation of the right plan is very important because a wrongly chosen strategy can affect the results in a very negative way. To keep the controversy going, the researcher chose a strategy to evaluate this study. The reason for this choice is that it serves as a guide and helps to conduct research in a more accurate way. It is also important to consider that the testing strategy also plays an important role in helping the researcher to set appropriate types of data collection methods. In addition, another compelling reason for the inclusion of a research strategy is that it supports the chosen method of pull-together research and in combination, these methods produce results in the best possible way. Keeping the research topic in mind to select the researcher had chosen the mono method. As with the mono method the researcher collects only one type of information from quantity and quantity. This method can be used to research the conflicting views that exist in the mono-method. For the researcher it is necessary to look at the choice- idea approach as the research depends on the size.

\subsection{Time Period}

The design used in this study is descriptive. The researcher used this because according to the data provided by Schwab [6], "The explanatory explanation is able to expand on the facts and information available which ultimately helps the researcher to reach a better conclusion". There are many designs that have been used by some researchers in the past. Keeping research in mind for a limited phase is used for this study, as the researcher can use balanced and multifaceted research in a differentiated way. It can help to monitor people's behavior. 


\subsection{Data Collection and Data Analysis}

Data collection source was researched. The rationale for the study was to examine the practice of employee motivation and to measure the performance behaviors in their organization. The research tool is a survey questionnaire, a tool in which key data is collected directly. A clear understanding of the researcher tested the worker's interest in their work. The research questionnaire contains questions on one of these variables so that you can find out more about the study participants. In addition, the questionnaires used were distributed online to respondents. Data analysis, the method of data analysis is limited because the hyporesearch paper created can only be tested and evaluated by mathematical strategies. In this regard, the SPSS tool for price analysis has been developed. The selected sample size was completed in this study by 80 . The respondents to the study were employees from the Banking Industry. The reason why employees choose the most accurate to include as study participants is that they are in a reliable position to answer what factors contribute to performance and job promotion that will affect their position in the organization.

\subsection{Behavioral Consideration}

By avoiding any issue that arises from a moral and ethical perspective, concern is addressed. This is the following;

Confidentiality - Ensuring that no information is provided by employees; whether professional or personal will be revealed.

Independence - The next concern is independence also considered. Following this, employees were also told that none of them were pressured by their participation.

The chapters conclude that this study followed the mono method and focused on conducting research with calculation strategies. The method used was drawable and the installed design defined it. In addition, 65 employees from the Banking Industry were contacted. Survey questionnaires were developed and distributed online and analyzed with the help of SPSS software.

\section{Data Analysis}

Data has been analyzed in different banking sector in order to conduct research and analyze results of performance appraisals.

The frequency shown in table 1 indicates that research comprises of young generation as cumulative percent is 66.2 which indicates a major presence of youth in filling out questionnaire of research. Gender diversity ratio has been kept approximately equal. This research is unique as due to COVID-19 impact and employee engagement and workforce management has been done as employee downsizing has started so therefore there is a need to revamp strategy and formulate employee retention and their reservation in order to keep workforce happy and adapt current situation with increase in profitability.

Table 1. Ages of Respondents.

\begin{tabular}{lllll}
\hline & Frequency & Percent & Valid Percent & Cumulative Percent \\
\hline 20 years to 30 years & 43. & 66.2 & 66.2 & 23.1 \\
31 years - 40 years & 15. & 23.1 & 96.2 & 89.2 \\
41 years - 50 years & 6. & 1. & 1.5 & 1.5 \\
50 years - 60 years or above & 65. & 100 & 100. \\
Total & & & 100.0 \\
\hline
\end{tabular}

Table 2. Gender.

\begin{tabular}{llll}
\hline & Frequency & Percent & Valid Percent \\
\hline Males & 38 & 58.5 & 58.5 \\
Females & 27 & 41.5 & 41.5 \\
Total & 65 & 100.0 & 100.0 \\
\hline
\end{tabular}

Table 3. Pay Scales

\begin{tabular}{|c|c|c|c|c|}
\hline & Frequency & Percent & Valid Percent & Cumulative Percent \\
\hline $20 \mathrm{~K}$ to $50 \mathrm{~K}$ & 48. & 73.8 & 73.8 & 73.8 \\
\hline $51 \mathrm{~K}$ to $80 \mathrm{k}$ & 10. & 15.4 & 15.4 & 89.2 \\
\hline $81 \mathrm{~K}$ to $100 \mathrm{~K}$ or above & 7. & 10.8 & 10.8 & 100 \\
\hline Total & 65 & 100 & 100. & \\
\hline
\end{tabular}

Table 4. Method of performance appraisal is implemented in your organization.

\begin{tabular}{lllll}
\hline & Frequency. & Percent & Valid Percent & Cumulative Percent \\
\hline Assessment Center Method. & 5.0 & 7.7 & 7.7 & 7.7 \\
I Do not Know. & 34. & 52.30 & 62.3 & 1.5 \\
BARS & 1.0 & 1.5 & 10.8 & 61.50 \\
Other. & 7 & 10.8 & 4.6 & 16.9 \\
360 degrees. & 3 & 4.6 & 6.2 & 76.90 \\
Bell Curve. & 11 & 6.2 & 16.9 & 100.0 \\
Human Resource Cost Accounting Method & 4 & 100.0 & 100.0 \\
Total & 65.0 & & \\
\hline
\end{tabular}


Table 5. Performance appraisal is for Employee Motivation.

\begin{tabular}{|c|c|c|c|c|}
\hline & Frequency & Percent & Valid Percent & Cumulative Percent \\
\hline Strongly Disagree. & 7 & 10.8 & 10.8 & 10.8 \\
\hline Disagree. & 2 & 3.1 & 3.1 & 13.8 \\
\hline Neutral. & 8 & 12.3 & 12.3 & 26.2 \\
\hline Agree. & 17 & 26.2 & 26.2 & 52.3 \\
\hline Strongly Agree. & 31 & 47.7 & 47.7 & 100.0 \\
\hline Total.. & 65 & 100.0 & 100.0 & \\
\hline
\end{tabular}

Table 6. Performance appraisal gives constructive criticism in a friendly and positive manner.

\begin{tabular}{|c|c|c|c|c|}
\hline & Frequency & Percent & Valid Percent & Cumulative Percent \\
\hline Strongly Disagree. & 2.0 & 3.10 & 3.1 & 3.1 \\
\hline Disagree. & 6 & 9.2 & 9.2 & 12.3 \\
\hline Neutral. & 18 & 27.7 & 27.7 & 40.0 \\
\hline Agree. & 28 & 43.1 & 43.1 & 83.1 \\
\hline Strongly Agree. & 11.0 & 16.9 & 16.9 & 100.0 \\
\hline Total. & 65.0 & 100. & 100.0 & \\
\hline
\end{tabular}

Table 7. I believe unfairness in performance appraisal process can lead to making a negative wave of impact on employee retention within organization.

\begin{tabular}{|c|c|c|c|c|}
\hline & Frequency & Percent & Valid Percent & Cumulative Percent \\
\hline Strongly Disagree. & 2 & 3.1 & 3.1 & 3.1 \\
\hline Disagree. & 2 & 3.1 & 3.1 & 6.2 \\
\hline Neutral. & 8 & 12.3 & 12.3 & 18.5 \\
\hline Agree. & 32 & 49.2 & 49.2 & 67.7 \\
\hline Strongly Agree. & 21 & 32.3 & 32.3 & 100.0 \\
\hline Total. & 65 & 100.0 & 100.0 & \\
\hline
\end{tabular}

Table 8. The monitoring of performance appraisals should be financial targets as well as behavioral aspects of employees.

\begin{tabular}{|c|c|c|c|c|}
\hline & Frequency & Percent & Valid Percent & Cumulative Percent \\
\hline Strongly Disagree. & 2 & 3.1 & 3.1 & 3.10 \\
\hline Disagree. & 6 & 9.2 & 9.2 & 12.30 \\
\hline Neutral. & 10 & 15.4 & 15.4 & 27.70 \\
\hline Agree. & 35 & 53.8 & 53.8 & 81.50 \\
\hline Strongly Agree. & 12 & 18.5 & 18.5 & 100.0 \\
\hline Total. & 65 & 100 & 100 & \\
\hline
\end{tabular}

Table 9. I am compensated fairly and recognized for my accomplishments.

\begin{tabular}{|c|c|c|c|c|}
\hline & Frequency & Percent & Valid Percent & Cumulative Percent \\
\hline Strongly Disagree. & 2 & 3.1 & 3.1 & 3.1 \\
\hline Disagree. & 6 & 9.20 & 9.20 & 12.30 \\
\hline Neutral. & 20 & 30.80 & 30.80 & 43.10 \\
\hline Agree. & 29 & 44.6 & 44.6 & 87.7 \\
\hline Strongly Agree. & 8 & 12.30 & 12.30 & 100 \\
\hline Total. & 65 & 100 & 100 & \\
\hline
\end{tabular}

Table 10. I am motivated to go an extra mile for work.

\begin{tabular}{|c|c|c|c|c|}
\hline & Frequency & Percent & Valid Percent & Cumulative Percent \\
\hline Strongly Disagree. & 1 & 1.5 & 1.5 & 1.5 \\
\hline Disagree. & 7 & 10.8 & 10.8 & 12.3 \\
\hline Neutral. & 14 & 21.5 & 21.5 & 33.8 \\
\hline Agree. & 30 & 46.2 & 46.2 & 80. \\
\hline Strongly Agree. & 13 & 20.0 & 20.0 & 100 \\
\hline Total. & 65 & 100 & 100 & \\
\hline
\end{tabular}


Table 11. I feel encouragement to come up with new and better way of doing things in my current employment.

\begin{tabular}{|c|c|c|c|c|}
\hline & Frequency & Percent & Valid Percent & Cumulative Percent \\
\hline Strongly Disagree. & 2. & 3.1 & 3.1 & 3.1 \\
\hline Disagree. & 5. & 7.7 & 7.7 & 10.8 \\
\hline Neutral. & 12 & 18.5 & 18.5 & 29.2 \\
\hline Agree. & 31 & 47.7 & 47.7 & 76.90 \\
\hline Strongly Agree. & 15 & 23.1 & 23.1 & 100 \\
\hline Total & 65 & 100. & 100 & \\
\hline
\end{tabular}

Table 12. Performance appraisal negatively or positively affects the moral life of employees.

\begin{tabular}{llllll}
\hline & Frequency & Percent & Valid Percent & Cumulative Percent \\
\hline \multirow{6}{*}{ Validity } & Strongly Disagree. & 1 & 1.5 & 1.5 & 1.5 \\
& Disagree. & 1 & 1.5 & 3.1 & 1.5 \\
& Neutral. & 6 & 9.20 & 9.20 & 12.30 \\
& Agree. & 29 & 44.6 & 44.6 & 43.1 \\
& Strongly Agree. & 28 & 43.1 & 100 & 100 \\
\hline
\end{tabular}

Table 13. There should be a regular evaluation and feedback on quarterly basis so that employee may have a chance to improvement.

\begin{tabular}{llllll}
\hline & & Frequency. & Percent. & Valid Percent. \\
\hline \multirow{4}{*}{ Valid } & Disagree. & 1 & 1.5 & 1.5 & 1.5 \\
& Neutral. & 5 & 7.7 & 7.7 & 9.2 \\
& Agree. & 36 & 55.4 & 55.4 & 35.40 \\
& Strongly Agree. & 23.0 & 35.40 & 100.0 \\
\hline
\end{tabular}

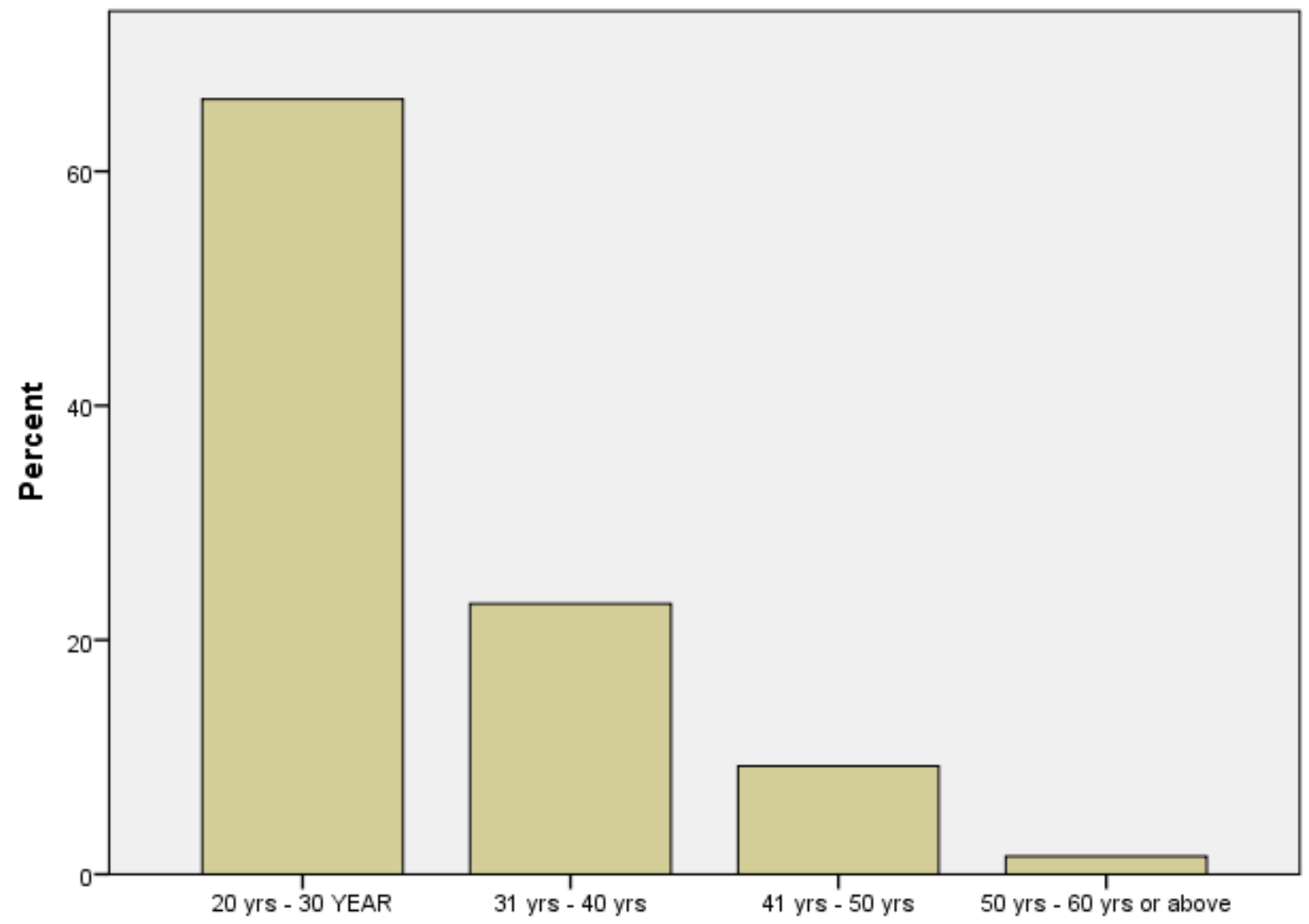

Figure 4. Age of Respondents.

1. Ages of Respondents were 60\% 20-30 years people.

2. Data has been collected from different Banks in order to strengthen research. 


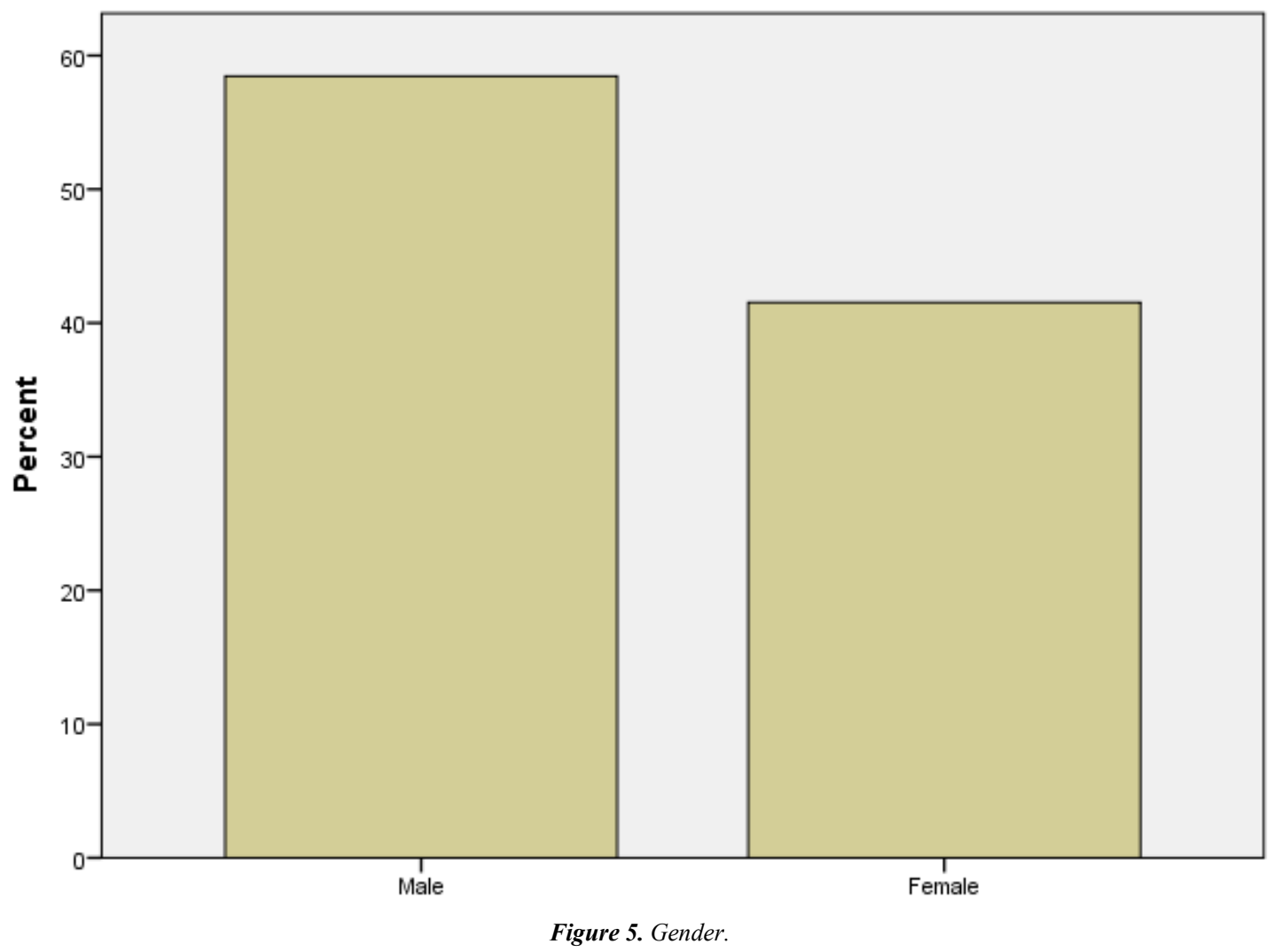

1. Symmetry has been between male and female officers;

2. $41.5 \%$ comprises of female population and $58.5 \%$ were of male population.

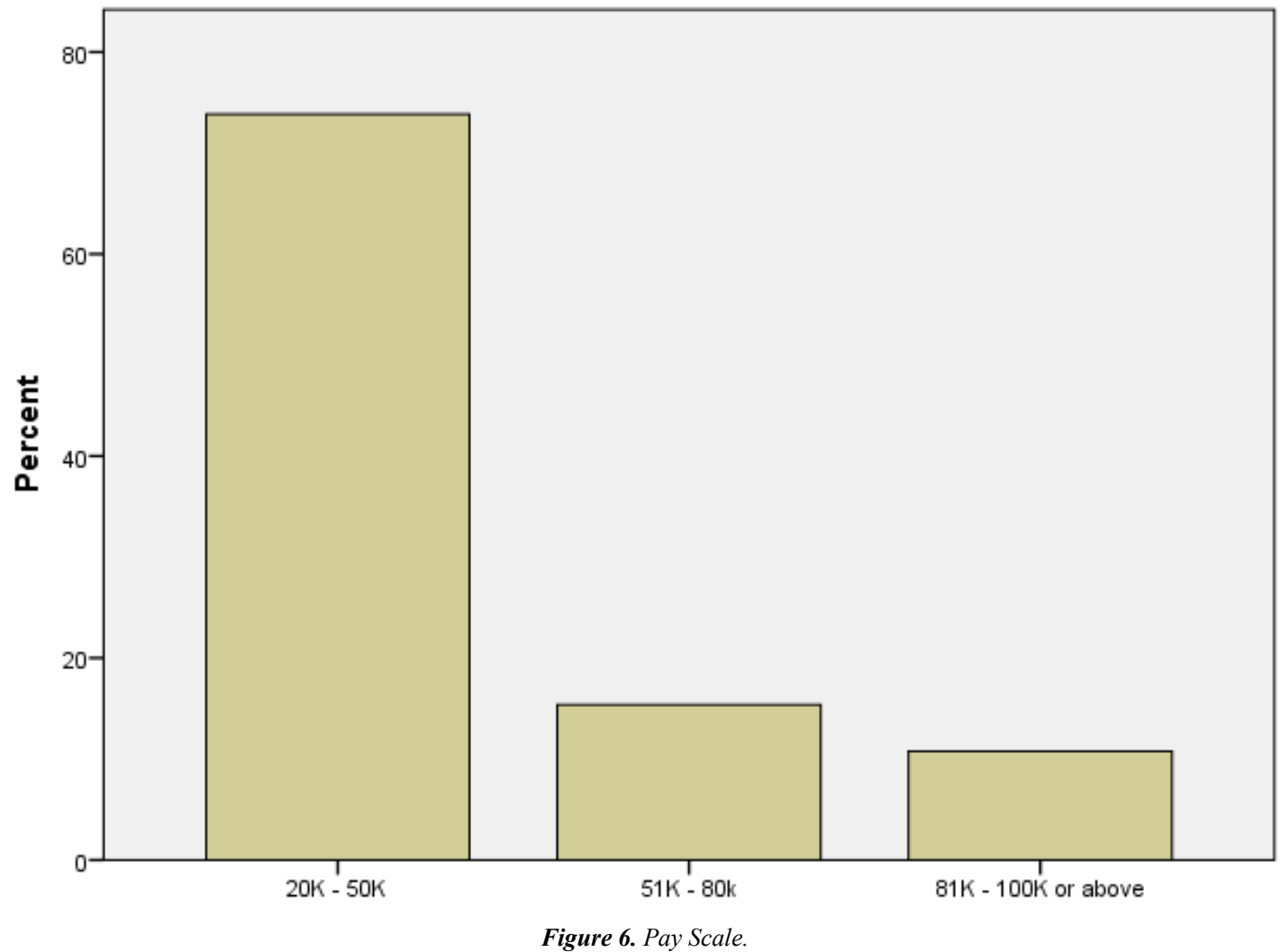

1. $73 \%$ of the bankers have a Pay Scale between $20 \mathrm{k}$ to $50 \mathrm{k}$.

2. Only $26.2 \%$ bankers having pay scale above $50 \mathrm{k}$. 


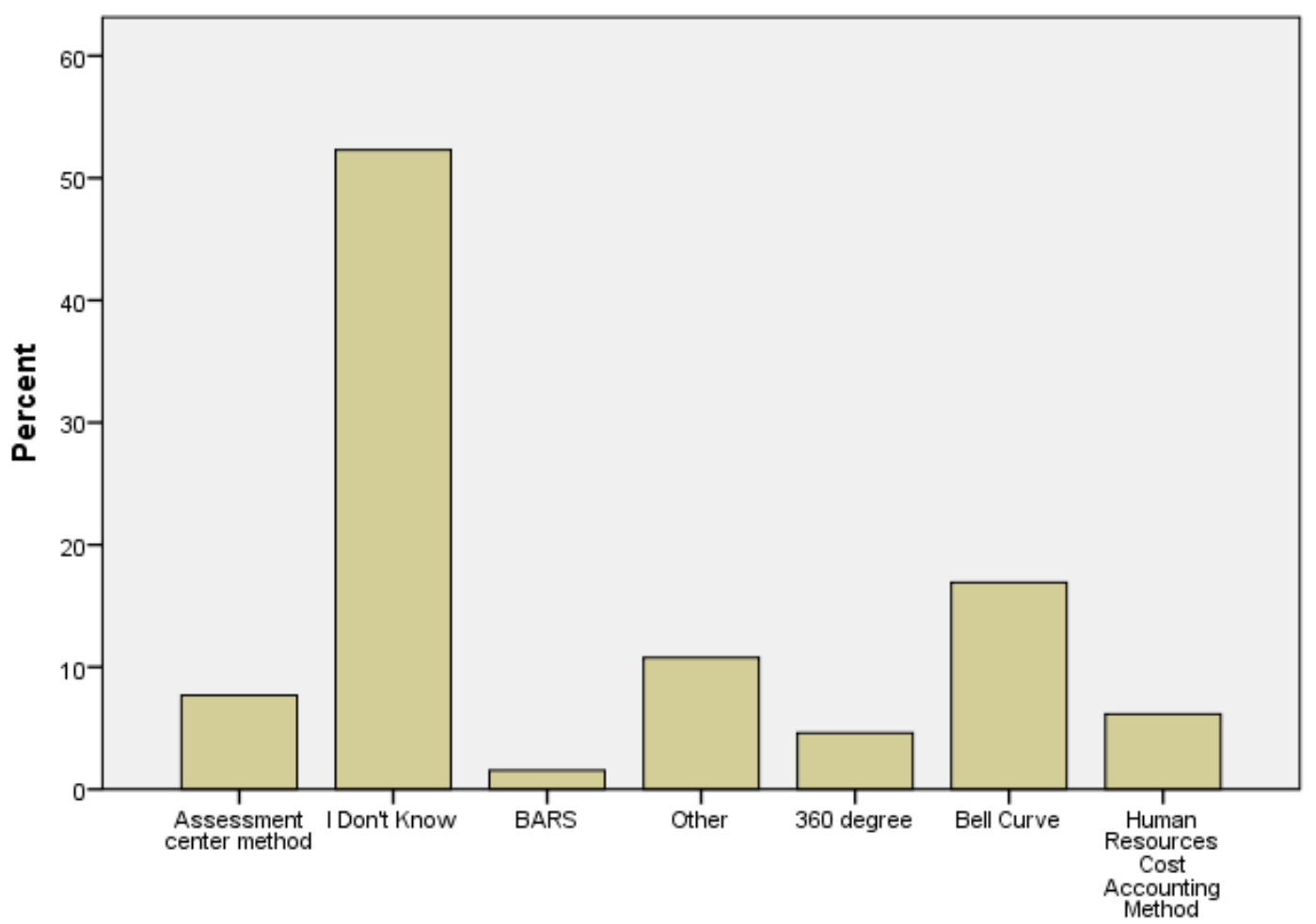

Figure 7. Performance Appraisals implemented in organization.

1. Majority of the employees do not know about the current performance appraisal method d in the organization.

2. Many employees from same bank chose different appraisal method.

3. This shows that majority of employees in the banks are not aware about their appraisal method.

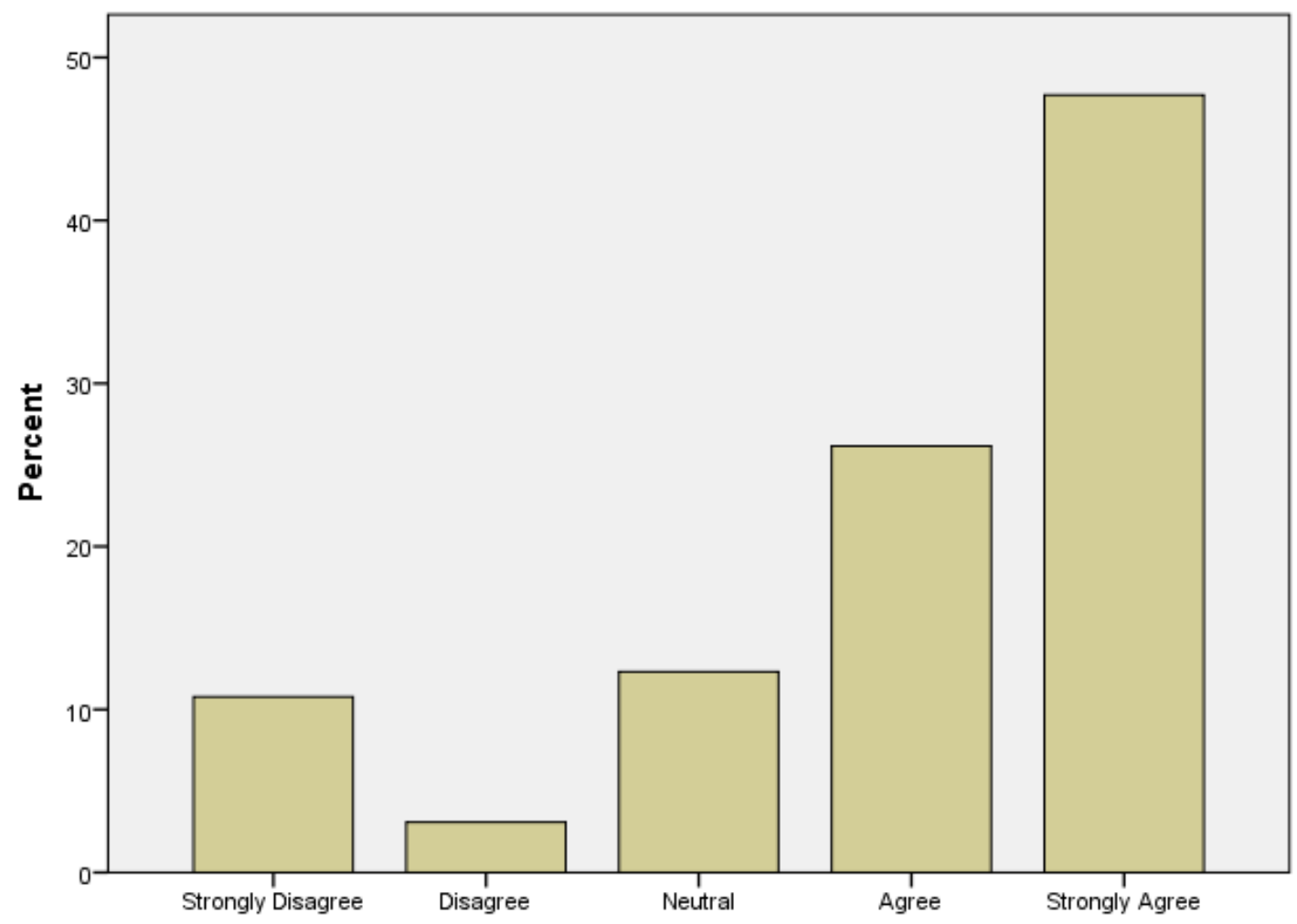

Figure 8. Performance Appraisal is for employee motivation.

1. Research shows that majority of the employees think that performance appraisals is for the employee motivation factor.

2. Only few were disagree from the statement. 


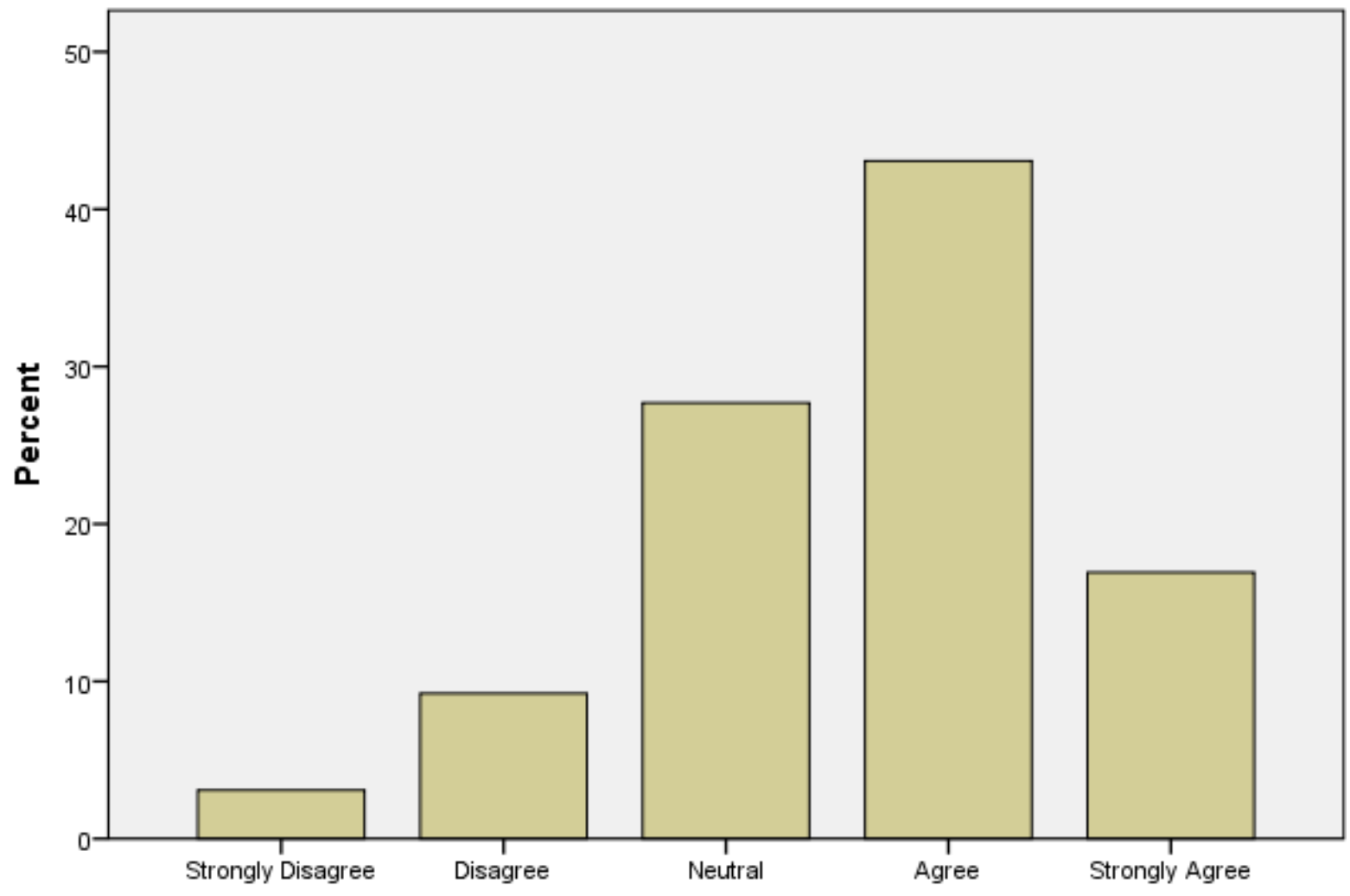

Figure 9. Performance appraisals gives constructive criticism in a friendly and positive manner.

It shows that majority of the employees think that appraisal gives constructive criticism in a friendly and a positive manner. less population disagrees with the statement.

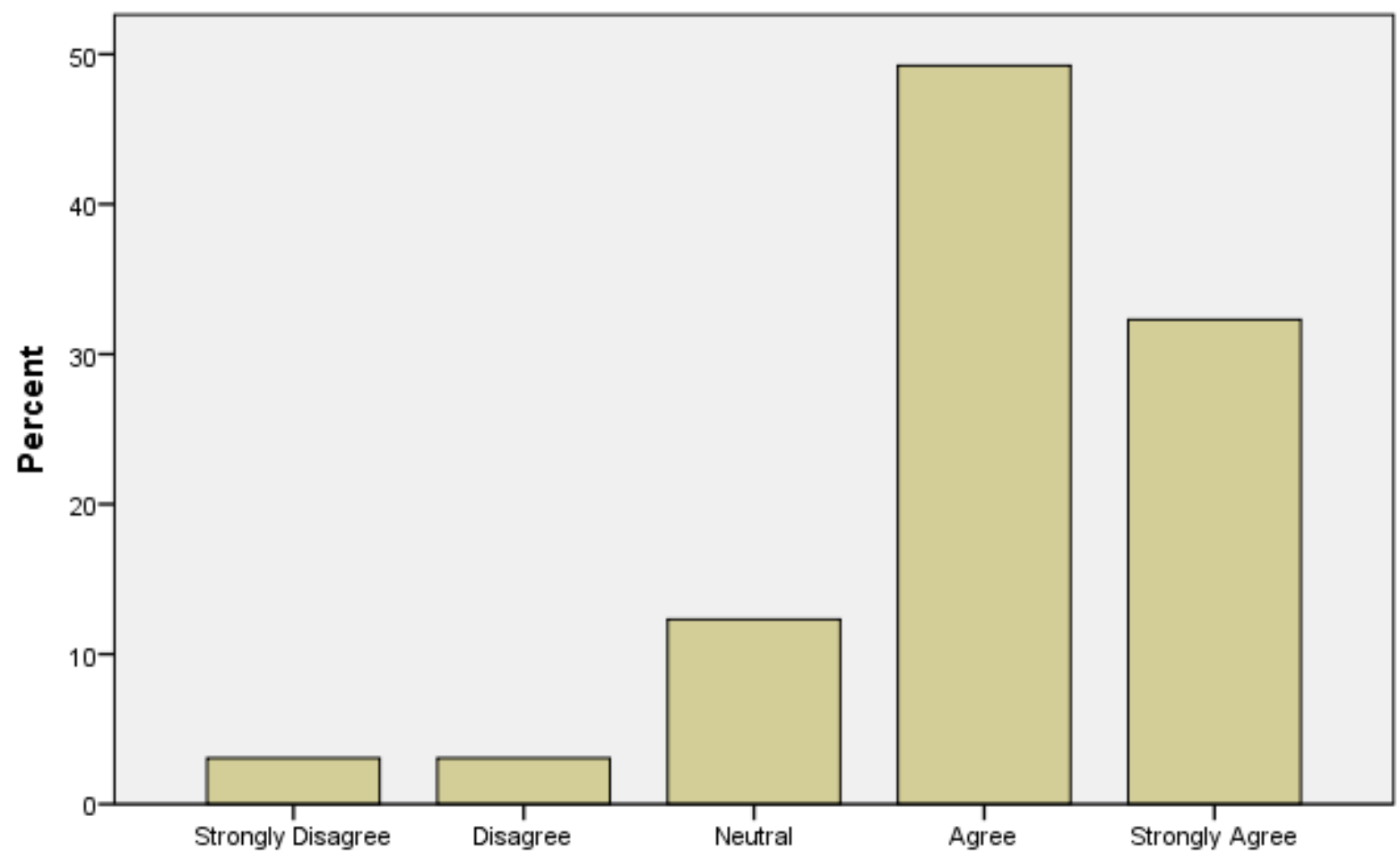

Figure 10. Performance Appraisals can lead to negative wave of impact on employee retention within an organizations.

1. Majority of the employees have the understanding that unfairness in the performance appraisal process can lead to negativity in employees.

2. Same as other only few disagrees with this statement. 


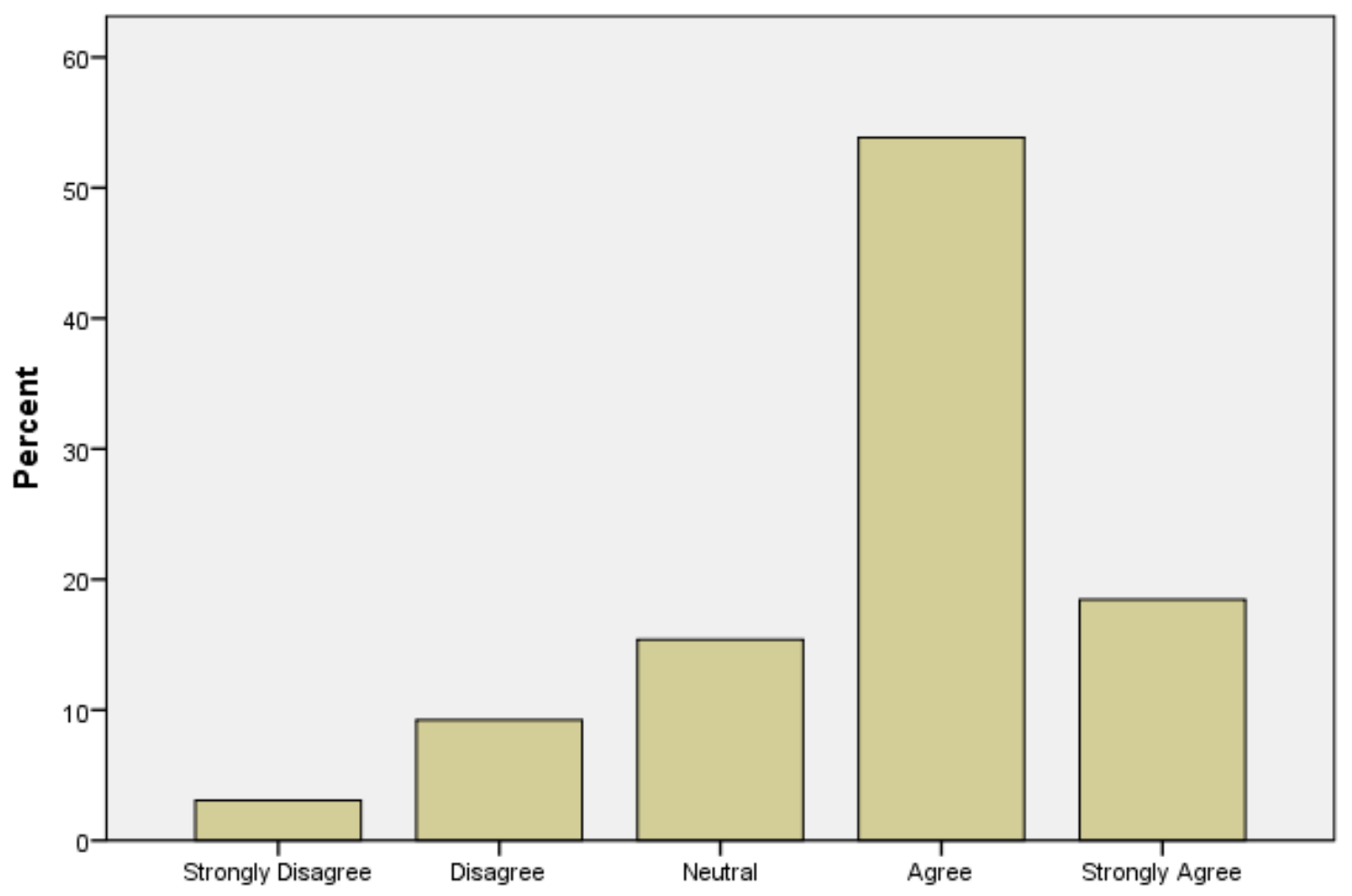

Figure 11. The monitoring of performance appraisals should be financial targets as well as behavior aspects of employees.

Majority of the employees agreed with performance appraisal should be financial as well as behavioral aspects of employees.

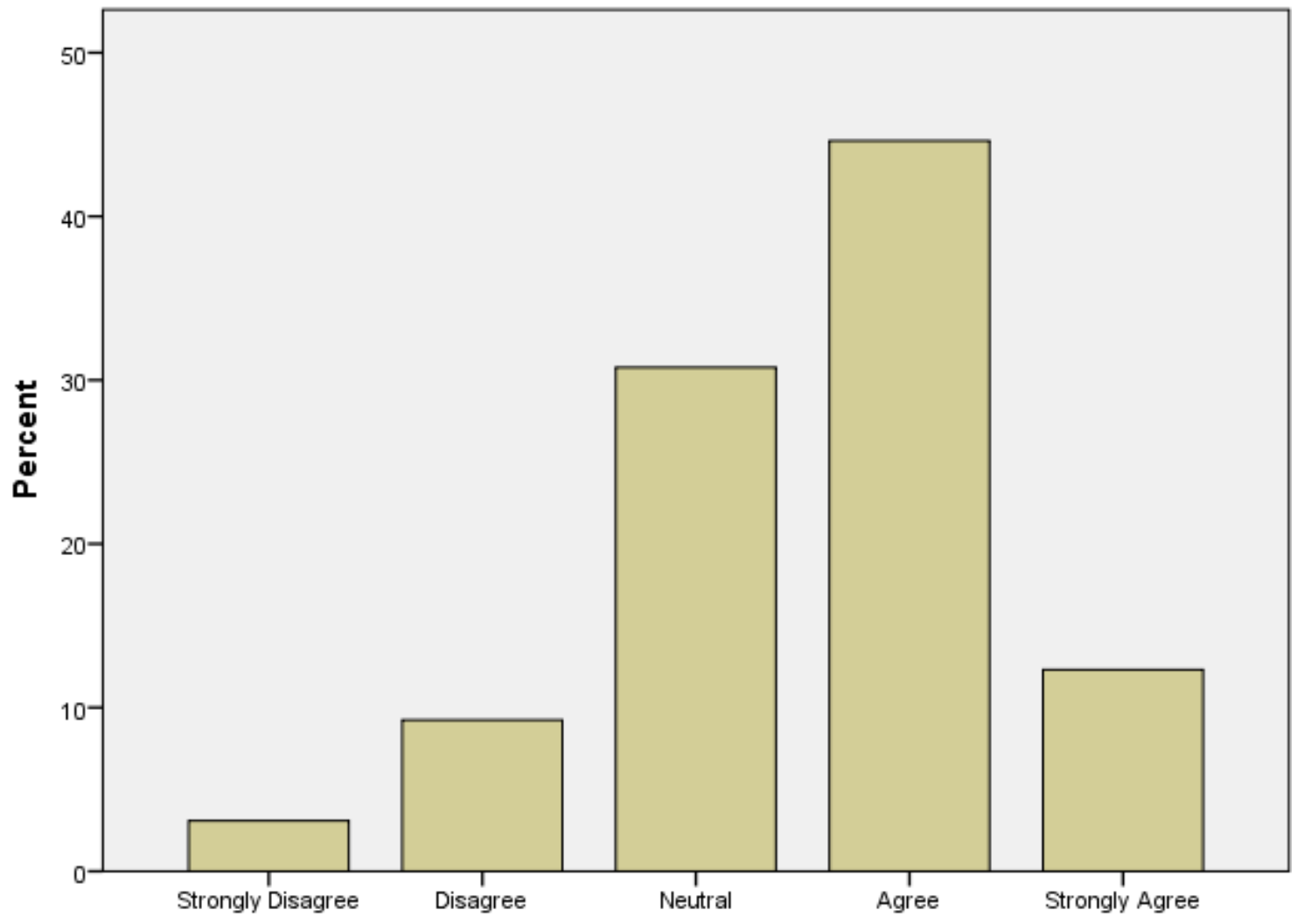

Figure 12. I am compensated fairly and recognized for my accomplishments.

1. Employees from these banks believe that they are compensated fairly and recognized for their accomplishments.

2. However $30 \%$ of the total population were neutral that means they have a mix thinking opinion of this statement. 


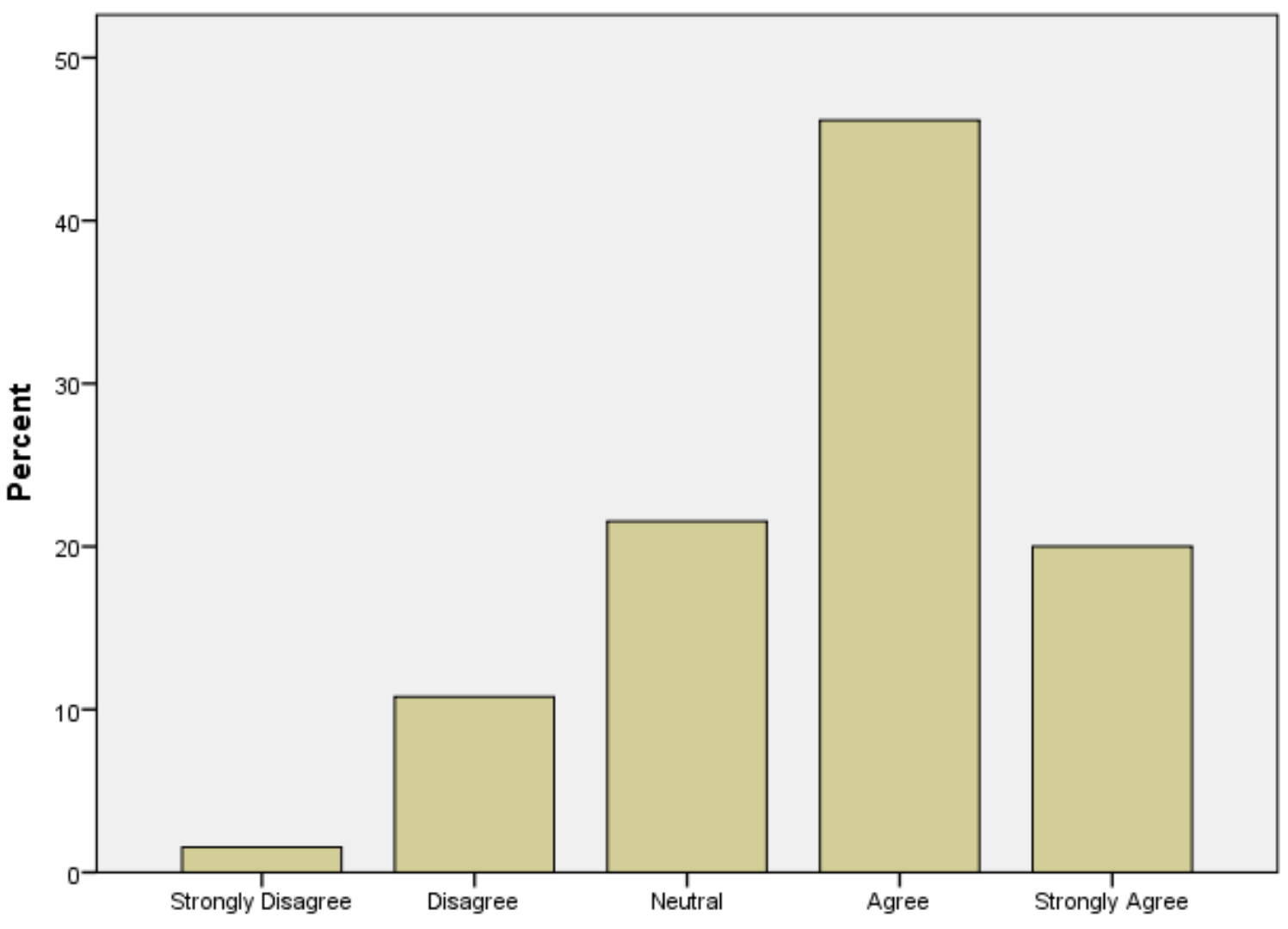

Figure 13. I am motivated to an extra mile at work.

1. Employees believe that they are motivated go an extra mile at work.

2. $20 \%$ of the employees strongly agrees on the statement.

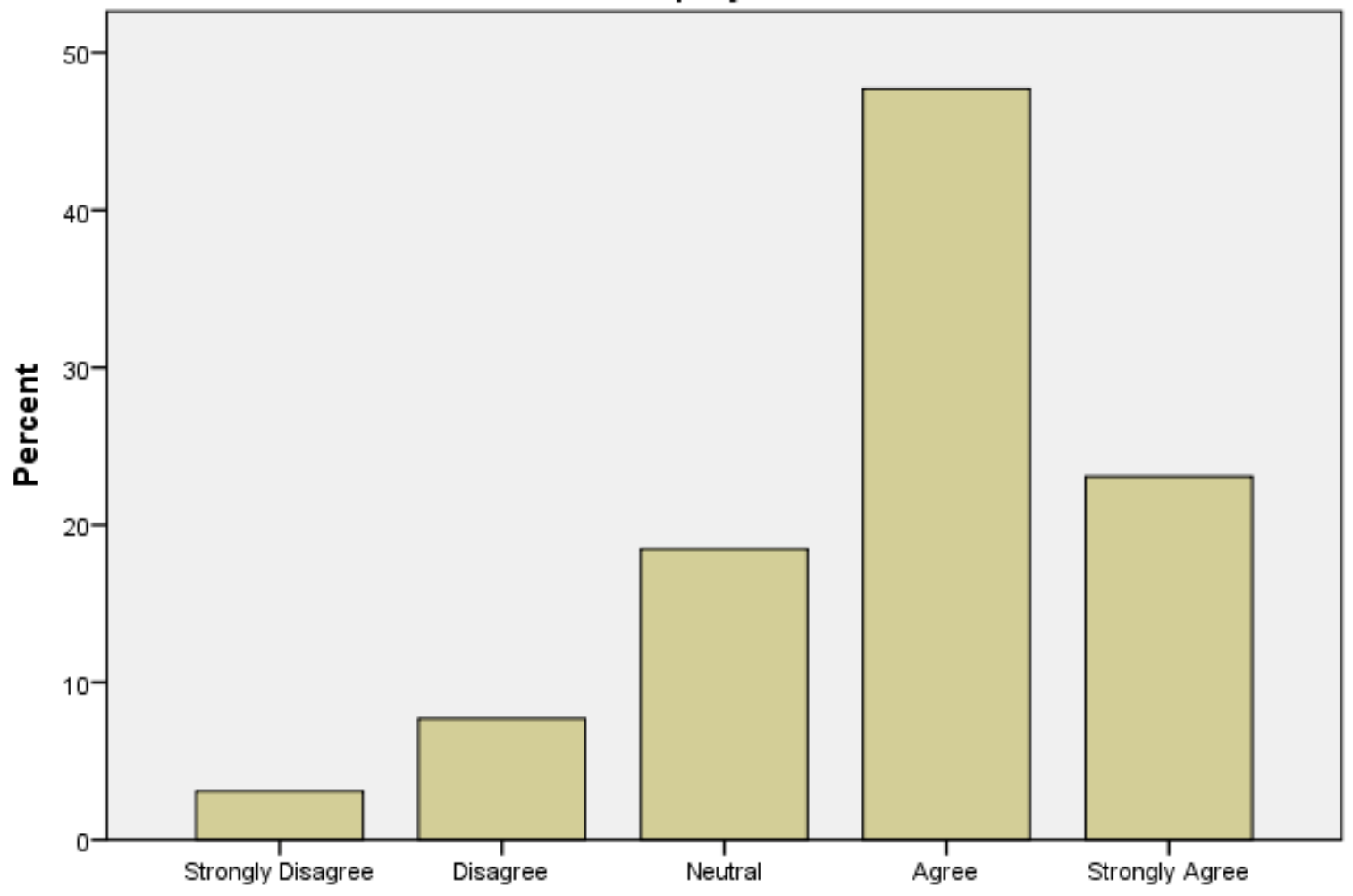

Figure 14. I am encouraged to come up with the new and better ways of doing things in my current employment.

Data shows that employees are encouraged to go up with Ideas and better ways of doing things. 


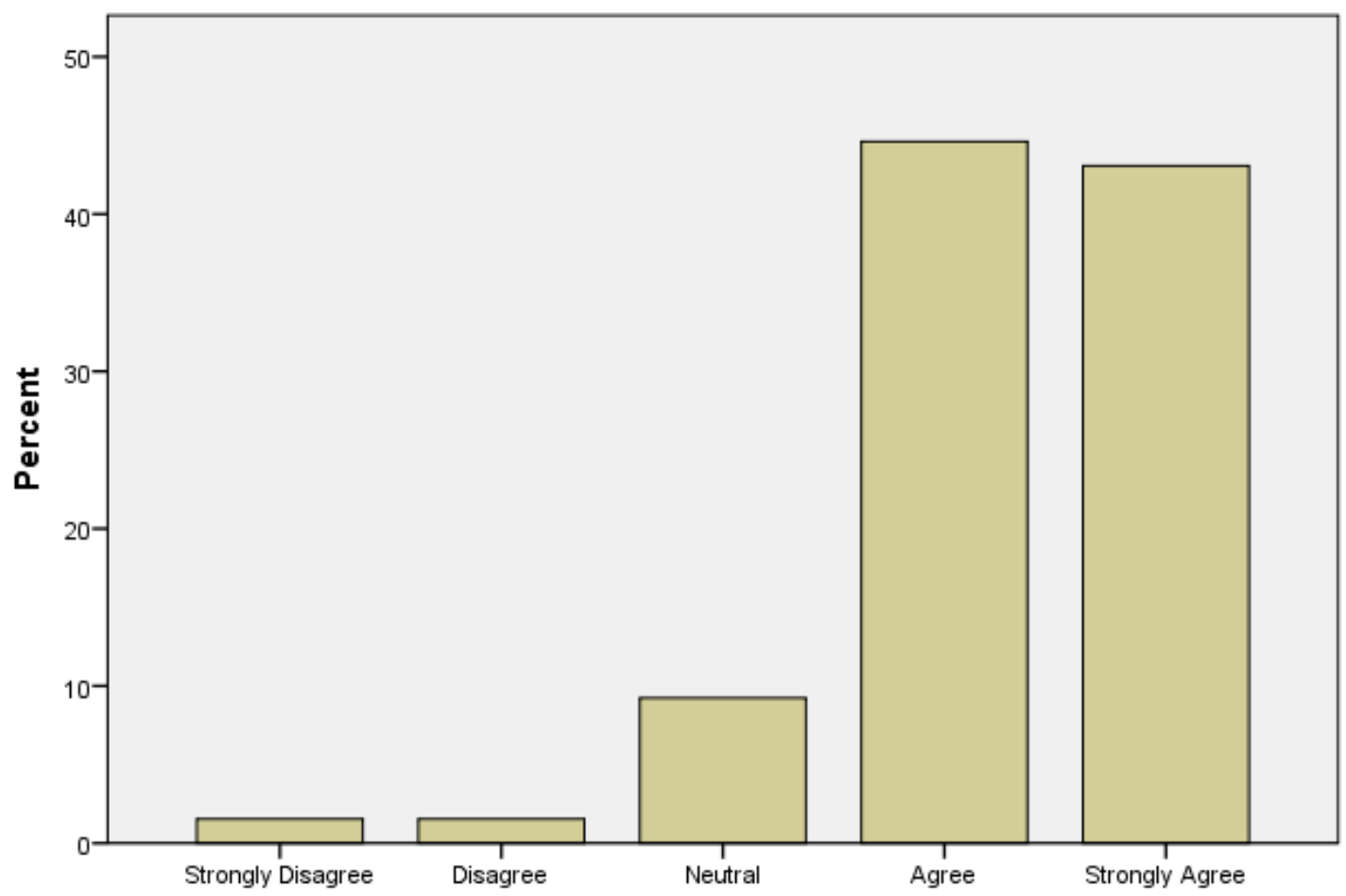

Figure 15. Performance appraisal negatively or positively effects the moral life of employees.

1. Employees believe that Performance appraisal has serious outcomes on moral life of an employee.

2. It can affect any employee positively and negatively both ways so therefore it should be un biased.

3. Many organizations does not evaluate their employees regularly instead they evaluate their employees at the time of appraisal.

4. Data shows that employee wants to be evaluated regularly to be updated and to get a chance to improve their performance.

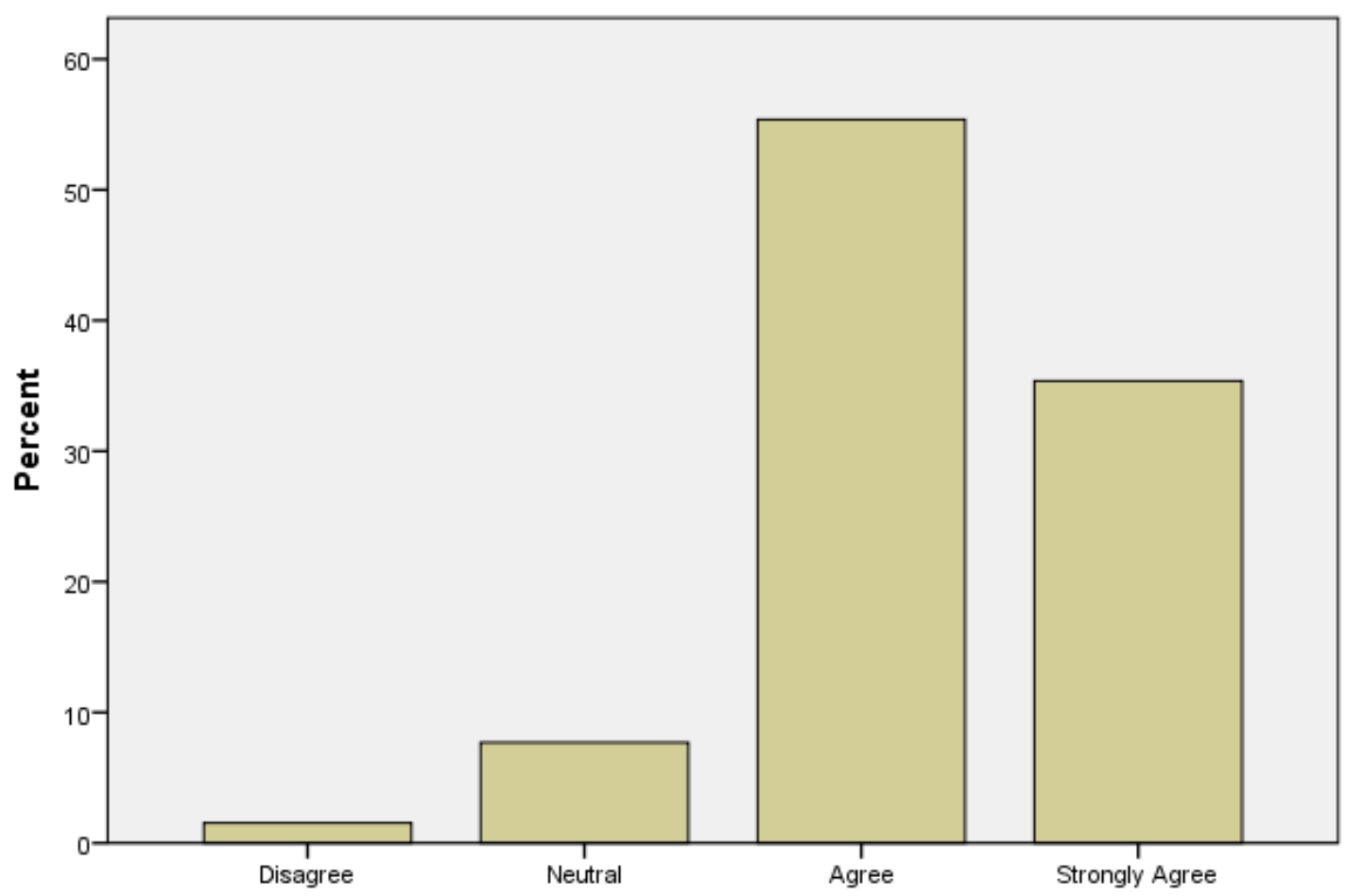

Figure 16. There should be regular evaluation and feedback on quarterly basis so that employees may have a chance to improve.

\section{Conclusion}

This study was conducted to analyze the performance appraisal methods used by various banks and how well their employees are aware and satisfied with the evaluation 
methodology used in the organization and have sufficient motivation for his work. Three well-known banks were selected for the study and questions were raised among the staff of these banks. By conducting research, it is clearly evident that performance appraisal has an impact on employee motivation.

Keeping in view of current literature we have concluded that there should be a new appraisal method in combination of 360 degree appraisal and Human Resource Cost Accounting method (staff compensation method) in terms of setting questions in digital format to peer staff keeping in view COVID-19 and confidentiality reason to award them $50 \%$ weightage and assign remain to Human Resources Cost Accounting method in order to evaluate value addition contributed by staff if an employee is not contributing in financial then its indirect contribution shall be evaluative by using qualitative technique.

Research data shows that the majority of employees in these organizations do not know what method of evaluation is used in their organization, more than $50 \%$ of the 65 people who did not know about the evaluation process used in their organization.

According to the survey the majority of employees other than those unfamiliar with the current organizational assessment methods have chosen different assessment methods, and different results were observed in the same organization.

Appraisal method in any organization definitely impacts employee behavior and his performance if financial sectors appraise and provides an opportunity to employees to grow in their organization so therefore employee retention ratio will be more and work efficiency would be increased using this new appraisal method because employee can easily judge his output and maintain healthy culture and environment accordingly with keeping an eye on his performance parameter of his contribution to organizational profitability.

\section{Future Work/Suggestions}

Keeping in view of technology and current pandemic situation it is essential to develop new appraisal method as suggested and digitalize data of appraisal cycle and employee feedback on appraisal cycle in order to develop more questionnaire and change existing banking structure so that in pandemic situation employee can be more fruitful in making organization profitable and it reduces resignation ratio and downsizing of employees. It is suggested to allocate points on different on key parameters of appraisal and counter check it with employees form of appraisal and appraisal of employee as suggested peer staff. In case of contradiction above $15-20 \%$ HR manager shall be involved and take a decision by hearing the case of an employee.

It is for human resource development in the sense of identification of employees' behavior and character and training them skills and culture of organization, training and teaching skills polish employee development. More over manager trainings and ambiance of environment can be improved by teaching them techniques for training them skills for improvement of organizational environment and culture in order to improve organizational culture and ambiance.

\section{References}

[1] Gunkel, M., Lusk, E. J., Wolff, B., \& Li, F. (2007). GenderSpecific Effects at Work: An Empirical Study of Four Countries. Gender, Work and Organization, 14: 56-79.

[2] Meier, Kenneth J. \& Hicklin. Alisa. (2008). Employee Turnover and Organizational Performance: Testing a Hypothesis from Classical Public Administration. Journal of Public Administration Research and Theory, Vol. 18, Issue 4, pp. 573-590. https://ssrn.com/abstract=1271029.

[3] Adams, John, Khan, Hafiz T. A. and Raeside, Robert (2014) Research methods for business and social science. Sage, London, UK. ISBN 9788132113669. Management and Business Research by Smith and Thrope. http://www.uk.sagepub.com/books/Book242499.

[4] Mark Easterby-Smith, Richard Thorpe \& Paul R Jackson. (2015). Management and Business Research. SAGE Publications.

[5] Joseph F. Hair (Jr.), Bryan A. Lukas, Kenneth E. Miller, Robert Bush, David Ortinau. (2011). Marketing Research. (2011). ( $3^{\text {rd }}$ ed.).

[6] Ray R. Sturm. (2017). Journal of Economics and Finance. 41, pages $257-275$.

[7] OECD. (2021). https://www.oecd.org/coronavirus/en/

[8] Saba Gulzar, Dr. Avinash and Dr. Tariq. (2017). Impact of performance appraisals on employee retention. Journal of Independent Studies and Research-Management, Social Sciences and Economics. Vol. 15. No. 1.

[9] R Pooja Dangol. (2021). Role of Performance Appraisal System and Its Impact on Employees Motivation. Vol. 2. No. 1.

[10] Anker, T. B. (2021). At the boundary: Post COVID business and management research in Europe and beyond. European Management Journal 39 (2) 171-178.

[11] Asfahani, A. (2021) The impact of COVID-19 on the decision making for the customer relation management in the middle east. Journal of Management and Information Decision Sciences. 24 (3) 1-11.

[12] Ranf D., Mănescu G., \& Badea D. (2021). Specific Business Continuity Management Practices During the COVID-19 Pandemic Crisis. Revista Academiei Forțelor Terestre, 26 (1), 62-68. https://doi.org/10.2478/raft-2021-0010.

[13] SHRM (2020). Society for Human Resource Management Retrieved. https://www.shrm.org/pages/default.aspx.

[14] Anthony Michael Bennett. (2021). Journal of Human Resource Management. Vol. 9 (3): 58-63.

[15] Chyung, S. Y. (2005). Human performance technology: From Taylor's scientific management to Gilbert's behavior engineering model. Performance Improvement, 44 (1), 23-28. DOI: $10.1002 /$ pfi.4140440109. 